\title{
ON THE NEMATOCYSTS OF HYDROMEDUSAE
}

\author{
By F. S. Russell, F.R.S. \\ Naturalist at the Plymouth Laboratory
}

(Text-figs. I-88)

In view of the possible use of nematocysts as characters for showing phylogenetic relationships among medusae (Weill, 1934), or even for the differentiation of species (Papenfuss, 1936), it is desirable that our knowledge of the nematocysts of medusae should be increased. I have accordingly examined the nematocysts in a number of species of Hydromedusae occurring at Plymouth.

Examination was always made on living material from which the portions to be examined, such as tentacles and mouth lips, were dissected. The dissected parts were placed on microscope slides, sometimes in sea water and sometimes in distilled water, and various stains such as magenta, methylene blue, and neutral red were used. Generally it was found that magenta and distilled water produced the best results for showing the minute structure of the nematocyst. The proportions of the nematocyst were first drawn under a monocular microscope with a camera lucida, and the slide was then transferred to a Leitz binocular microscope for more detailed examination. A $2 \mathrm{~mm}$. apochromatic oil immersion objective was used, with $\times$ Io eyepieces. Illumination was obtained with a "pointolite" and increased definition was helped by the use of a substage screen-a Wratten filter, Rheinberg No. 2 Blue Disc.

It is necessary to emphasize that observations were made on fresh material, since, as pointed out by Weill (1934, p. 30), fixation or desiccation may modify the form of the nematocyst. The nematocysts of most medusae are very small, the majority being less than $15 \mu$ in length, and certain difficulties may be experienced. One of the chief dangers is that if insufficient material is examined one type of nematocyst, at least, may be overlooked. I have on several occasions found an additional type of nematocyst, which I had not observed when examining previous medusae of the same species. This is generally due to the fact that different types of nematocysts may resemble one another in outline when in the undischarged ${ }^{\star}$ state. Unless, therefore, a very large number of nematocysts are discharged, that type which happens to be the least frequent may easily be overlooked if none are discharged. It was, for instance, only after I had examined a number of specimens of Phialidium hemisphericum that I found a few atrichous nematocysts among the very abundant mastigophores and later found that they were quite common.

* The terms discharged and undischarged are used here in preference to exploded and unexploded. 
Considerable difficulty was also experienced in this species, as in some other Leptomedusae, in deciding whether the nematocysts were microbasic mastigophores or basitrichous haplonemes, i.e. whether the basal portion of the discharged thread was thicker than the remainder of the thread. A number of Phialidium were examined at different times and the conclusion was reached that, immediately after the discharge of the nematocyst the basal portion of the thread was considerably thicker than the terminal portion. But there was often subsequent swelling of the terminal portion, whether through increased pressure of the coverglass, or for other reasons, and the terminal portion assumed the same thickness as the basal portion. There must, therefore, always be some doubt whether the classification of some Leptomedusan nematocysts into microbasic mastigophores and basitrichous haplonemes is reliable. A similar increase in diameter in the terminal portion of the thread is referred to on page $15 \mathrm{I}$ in the microbasic euryteles of Zanclea costata, and it was noticed in other species. Weill (1934, pp. 58, I53) says that the diameter of the thread can only be accurately seen after staining with neutral red, but I found that this frequently caused swelling.

Difficulties of rather a similar nature arose concerning the microbasic mastigophores of Leuckartiara octona. Weill (1934, p. 392) records that he only found microbasic mastigophores in this species. In the first specimens that I saw, however, there was no doubt that all the discharged nematocysts seen were not mastigophores but microbasic euryteles. But, on examining more specimens, I found some microbasic mastigophores, and I was then in some doubt whether these might not really have been microbasic euryteles in which the basal portion was abnormal and had not swollen to its full extent, or whether perhaps the nematocysts were incompletely developed. These doubts were enforced when I found among the microbasic euryteles of Rathkea octopunctata some in which the walls of the base were parallel, and also some intermediate stages between this and the typical euryteles. A subsequent examination of more Leuckartiara showed that, in this species at any rate, the mastigophores were of a very slightly different shape from the euryteles and could eventually be distinguished in the undischarged state.

It was found that in one species, Amphinema dinema, one of the nematocyst types was present in the medusa just liberated from the hydroid, but absent in the adult medusa. The newly liberated medusa possessed microbasic euryteles and desmonemes; the adult had only microbasic euryteles. The hydroid had, however, both kinds of nematocysts, and it is probable that the nematocysts of the hydroid migrate into the developing bud and that the medusa itself when liberated is only capable of making one kind. How exactly the desmonemes disappear in the medusa is uncertain, but it is just possible that they remain throughout the life of the medusa and were not noticed owing to their numbers being swamped by those of the nematocysts made by the medusa as it grew.

Another possibility of error is due to the occurrence in a medusa of nemato- 
cysts which are not its own. I have on several occasions found, in the manubrium and hollow basal portions of the tentacles, nematocysts of quite a different type from those typical of the species of medusa in question. Thus I have seen large stenoteles in both Leuckartiara octona and Amphinema dinema. These must undoubtedly have been ingested by the medusa with its food. Usually these foreign nematocysts are obvious on account of their collapsed condition, but if they have been recently ingested they may lead to a source of error.

The nematocysts typical of any one species of medusa sometimes showed considerable differences between their range of size from one specimen to another. This is probably usually a function of the size, or age of the medusa, or its state of nourishment. For instance, the microbasic euryteles in $\mathrm{Am}$ phinema dinema just liberated from its hydroid were $6-7 \times 2 \mu$, whereas in the adult medusa they were $7-9.5 \times 2-3.5 \mu$; in one specimen of Saphenia the basitrichous haplonemes were mostly $\mathrm{I} 8-\mathrm{I} 9 \mu$ long, while in another specimen they ranged from 22 to $28 \mu$ long.

In the following pages accounts are given of the nematocysts from twenty species of medusae. In this paper I have followed Weill's classification, which, in spite of such difficulties as I have mentioned above, is extremely serviceable. It is quite to be expected that with the great variety of structure shown by coelenterate nematocysts it is impossible to make a rigid classification and intergrading types are sure to be found (e.g. Weill, 1934, p. 59). But on the whole his classification does enable one quickly to place a nematocyst in its right category. I feel, however, a little doubtful about trying to discriminate between homotrichous and heterotrichous forms in such small nematocysts as those of most medusae. It should be realized that in the minute structure of many of these nematocysts we are reaching the limit of comfortable visual observation. It thus becomes extremely difficult, and perhaps impossible, to decide the comparative lengths of the smaller spines or barbs owing to the effects of foreshortening when each spine is lying in a different plane. I have therefore purposely omitted any reference to homotrichy or heterotrichy in the following accounts, since I was never able to satisfy myself as to their validity.

In the following descriptions I have generally given only the types of the nematocysts and their measurements and location. It seemed unnecessary to attempt to describe in words their various shapes, when this has been shown in the accompanying figures. As I have already stated, the outlines of these figures were drawn with a camera lucida, but in order to eliminate personal error in the interpretation of the minute structure in the discharged nematocysts I have, for almost every drawing, called upon the help of independent observers who checked my drawings against the originals. For their kind assistance in this way I have especially to thank Mr E. Ford, $\mathrm{Mr}$ W. J. Rees and Mr G. M. Spooner.

As far as I could see, the number of spirals, when these occurred, on all the 
nematocysts examined was always three; this is in agreement with the statements of most workers. I have, however, in some drawings, where the basal portion of the thread was very narrow, only indicated the general appearance, as it was difficult to draw three spirals without spoiling the effect by running the lines together. In the accompanying figures all nematocysts, except where stated otherwise, are drawn to the same scale, so that the sizes of the nematocysts of the different species can easily be compared.

Measurements are only given to $0.5 \mu$ on account of the difficulty of making sure that the nematocysts were exactly orientated horizontally and showing their greatest width. Any attempt to do this by pressure is liable to distort the capsule.

No attempt has been made to depict accurately the course of the thread in the undischarged basitrichous haplonemes or mastigophores. They are shown merely as simple coils, whereas they are generally thrown into S-shaped loops. While the capsules are mostly drawn in lateral view, the coils thus shown give the impression produced when the capsule is looked at dorsoventrally.

This work must be regarded merely as a preliminary survey of the types of nematocyst present. No attempt has been made to obtain average sizes for the different species; this would involve measurements on great numbers of medusae of different sizes.

\section{ANTHOMEDUSAE}

\section{Steenstrupia nutans (M. Sars).}

There appear to be at least four kinds, stenoteles, ? anisorhize heterotrichous haplonemes, ? microbasic mastigophores or microbasic euryteles, and desmonemes (Figs. I-7).

Stenoteles: there is a large range of size shown by these nematocysts, which appear to be grouped roughly in two sizes:

Large: II-I6 $\times 9-13 \mu$ undischarged, II-I3 $\times 9-$ II $\mu$ discharged.

Small: 7-10 $\times 6-8 \mu$ undischarged.

? Anisorhize: II-I2 $\times 9 \cdot 5-10 \mu$ undischarged, $9 \times 8 \mu$ discharged.

While these appeared to be anisorhize after first discharge, the thread later swelled up. There were definite spirals of short spines at the base, but the spirals on the rest of the thread appeared to have no spines.

? Euryteles: $8-12 \times 3.5 \mu$ undischarged.

I had the same difficulty with these as in Rathkea; in some specimens they appeared as euryteles and in others as mastigophores.

Desmonemes: $6-7.5 \times 4.5-5.5 \mu$ undischarged. 

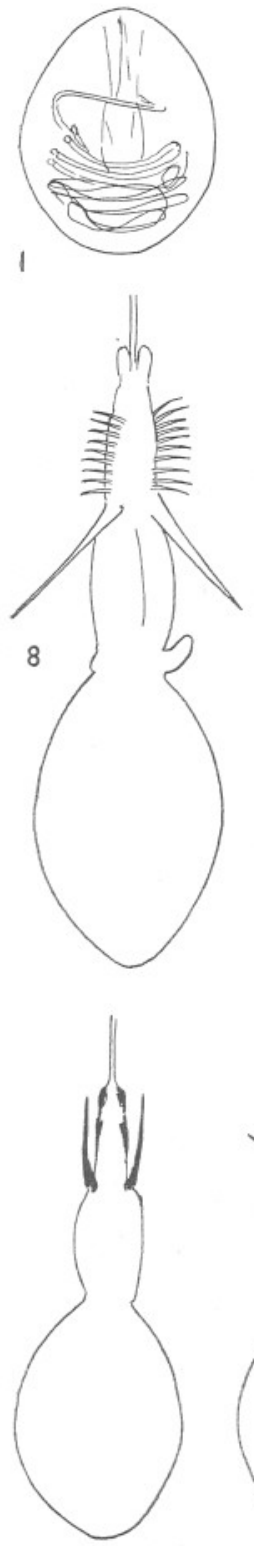

13

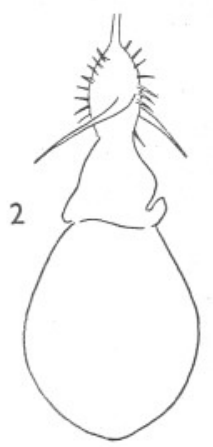

3
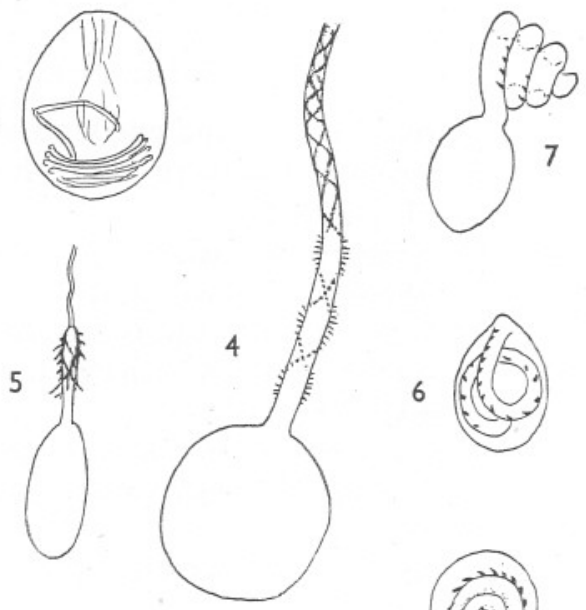

6
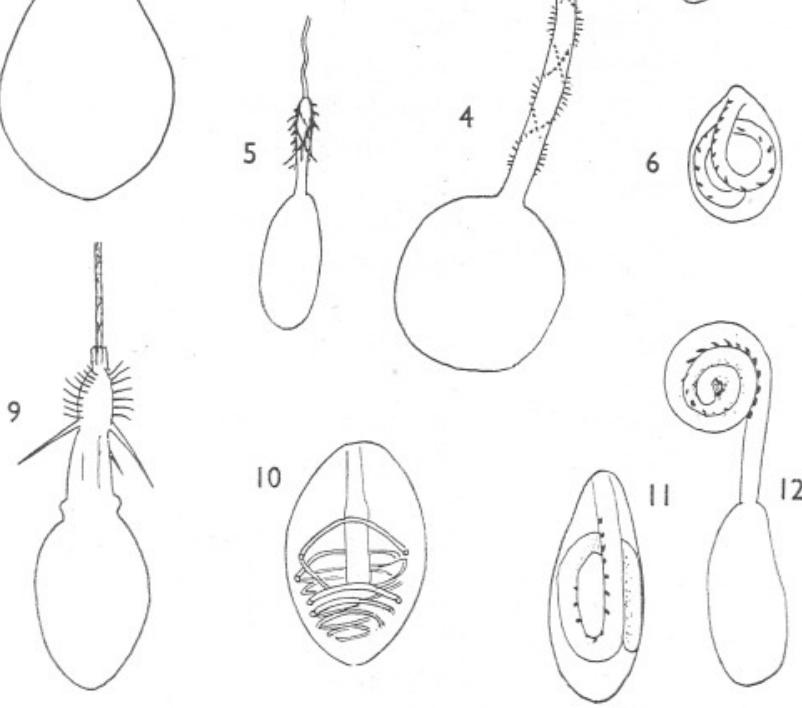

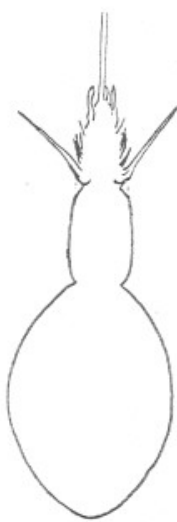

14

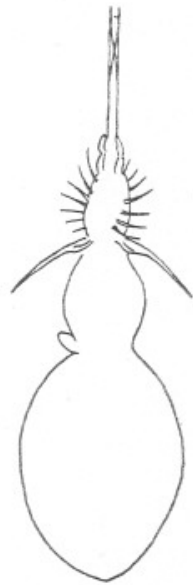

15

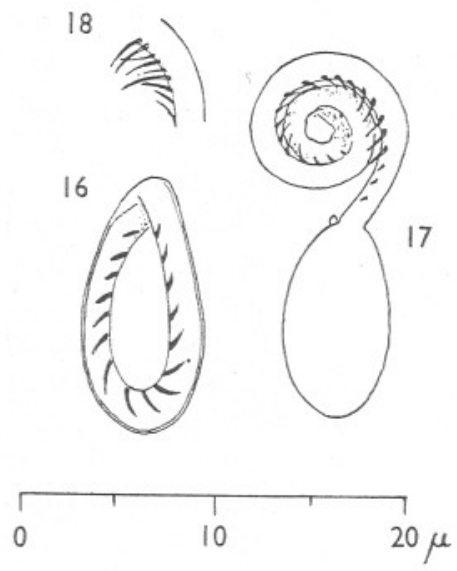

$20 \mu$

Figs. I-7. Steenstrupia nutans: I-3, stenoteles; 4, anisorhize; 5, ? eurytele; 6, 7, desmonemes. $\times$ ca. 2000.

Figs. 8-I2. Sarsia eximia: 8, large stenotele from hydroid; ro, small stenotele from hydroid; 9, stenotele from newly liberated medusa; II, I2, desmonemes from newly liberated medusa. $\times$ ca. 2000 .

Figs. 13-18. Purena gemmifera: $13-15$, stenoteles in process of discharge; 16,17 , desmonemes; I8, enlarged portion of desmoneme thread. $\times c a .2000$. 


\section{Sarsia eximia Allman.}

In the hydroid I only found one kind of nematocyst, viz. stenoteles. In the newly liberated medusa there were, however, two kinds, stenoteles and desmonemes (Figs. 8-I2).

HYDROID (Syncoryne eximia):

Stenoteles: these are of two sizes:

Large: $21 \cdot 5-26 \times 15-18 \mu$ undischarged.

Small: $12-13 \times 7 \cdot 5-9 \mu$ undischarged.

MEDUSA, newly liberated:

Stenoteles: these ranged in size from 9.5-16 6 6.5-10 $\mu$ undischarged. Most were $c a$. $13 \times 9 \mu$ undischarged; the smaller nematocysts may not have been fully developed.

Desmonemes: 9.5-12 $\times 4-5.5 \mu$ undischarged. Most were ca. $\mathrm{I} 2 \times 4.5 \mu$ undischarged.

I do not agree with Weill (1934, p. 385) as regards the structure of the stenoteles. I have discussed this below under Purena gemmifera.

\section{Purena gemmifera Forbes.}

Two kinds, stenoteles and desmonemes (Figs. I3-I8).

Stenoteles: these are of two sizes:

Large: $\mathrm{I} 6 \times \mathrm{I} 2 \mu$ undischarged.

Small: $13 \times 9-10 \mu$ undischarged.

Desmonemes: $13-14 \times 6-7 \mu$ undischarged.

While I agree with Weill (1934, p. 384) as regards the types of nematocysts present in this medusa, I cannot agree with him as regards the structure of the stenoteles in this species and in Sarsia eximia. Weill states that the small median spines are absent. They are in fact present and the stenotele is quite typical. The appearance or absence of the median spines is I think entirely due either to incomplete discharge of the nematocyst or to the incomplete development of the nematocyst. For instance, in a preparation in sea water and methylene blue, almost all the stenoteles were partially discharged with their posterior spines directed forwards. I was only able to find two fully discharged. In another preparation in distilled water and magenta, however, many were fully discharged with their basal spines directed backwards. In these the median spines were quite distinct. If the nematocysts are only partially discharged, the median spines all lie directed forwards over one another and each spiral appears only as a dark line. I have illustrated the various stages of discharge in Figs. I3-I5. In many instances the whole armature of the hamp was broken away from the nematocyst, indicating that the nematocyst was not completely developed and the walls of the hamp had not reached their full thickness and strength. 


\section{Zanclea costata Gegenbaur (?).}

I have examined a number of specimens newly liberated from the hydroid in the laboratory. The hydroid was the same as that described by Russell \& Rees (1936). There were three kinds of nematocysts, stenoteles, macrobasic telotrichous euryteles and ? atrichous haplonemes.

Stenoteles: $7-\mathrm{I} 3 \times 6-\mathrm{I} 2 \mu$ undischarged, 6-I I $\times 5-9 \mu$ discharged.

These were present in the exumbrellar armature.

Macrobasic euryteles (Figs. I9-22):

Capsule: $7-7 \cdot 5 \times 4 \cdot 5-5 \cdot 5 \mu$ undischarged, $5-6 \times 3-4 \mu$ discharged.

Length of hamp: $c a$. 25-30 $\mu$ discharged.

Ampulla: $4 \cdot 5-5 \times \mathrm{I} \cdot 5-2 \cdot 5 \mu$.

The three spirals of barbs were present on the ampulla and extended for a short way down the hamp as in Pteroclava krempfi (Weill, I934, p. 78). When first discharged the thread beyond the hamp is definitely thinner than the hamp itself. The thread, however, swells up later under pressure to the same thickness as the hamp. This increase in thickness of the thread under pressure possibly accounts for the differences in the observations of Weill and Allman (Weill, I934, p. 78 et seq.), but both these authors describe the ampulla in this much discussed species as having no barbs. Both Weill and Allman also give the length of the hamp as being much greater than in my specimens. These nematocysts occur in the cnidophores of the tentacles.

? Atriches: I only saw an occasional atriche and unfortunately obtained no measurements. They appeared to be extremely rare.

While discussing the nematocysts of Zanclea it will be convenient to answer a question raised by Weill (I936a) and Ranson (I937) concerning the nature of the exumbrellar nematocyst armature. The four exumbrellar groups of nematocysts are embedded in solid tissue and not in hollow sacs. This agrees with Weill's observation (I934, p. 420) on the American medusa. Allman (I87I, p. 224) states that the nematocysts are immersed in a clear fluid; they certainly have this appearance unless highly magnified.

A comparison between the American medusa as described by Weill (I934, p. 4I8) and the Plymouth medusa as described by Russell \& Rees (I936) is given below. Both descriptions refer to medusae just liberated from the hydroid:

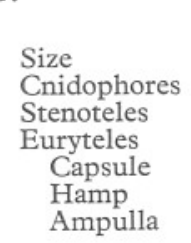

$$
\begin{aligned}
& \quad \text { Plymouth } \\
& 0.6-0.7 \mathrm{~mm} . \text { high } \\
& \text { I } 8-20 \times 13 \mu \\
& 7-13 \times 6-12 \mu \\
& \text { Telotrichous } \\
& 7-7.5 \times 4.5-5.5 \mu \\
& 25-30 \mu \text { long } \\
& 4.5 \times 5 \mu \text { long }
\end{aligned}
$$

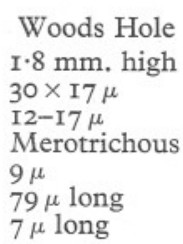

It can only remain a matter of opinion whether these differences should be regarded as of specific value, until a large number of medusae with two and four tentacles from different localities have been examined. Until we know 
what degree of constancy there is in these differences, any further discussion is at present valueless, but it should be borne in mind that mere size difference is of doubtful value.
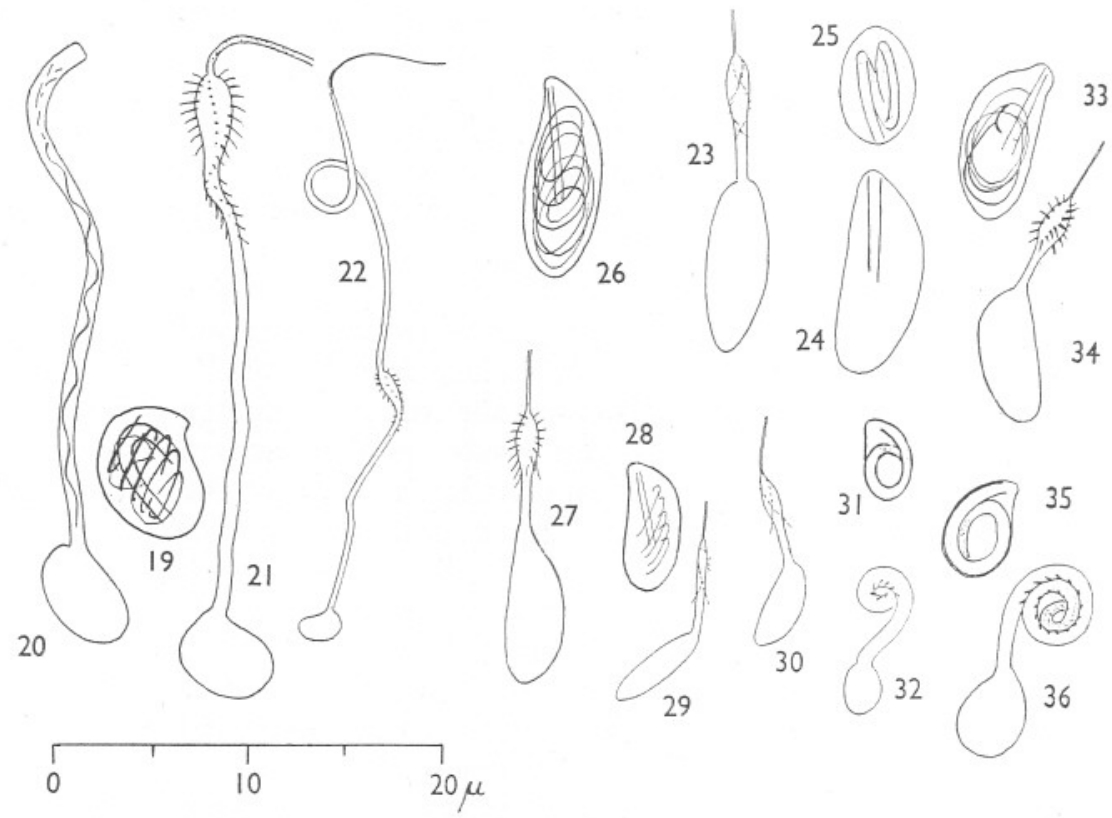

Figs. I9-22. Zanclea costata, newly liberated: I9-21, macrobasic euryteles, $\times$ ca. 2000; 22, macrobasic eurytele after pressure, $\times c a .900$.

Figs. 23-25. Bougainvillia britannica: 23, 24, microbasic euryteles; 25, desmoneme (dorsal view). $\times$ ca. 2000 .

Figs. 26-32. Rathkea octopunctata: 26, 27, microbasic euryteles from oral tentacles; 28, 30, microbasic euryteles from marginal tentacle; 29, ? microbasic mastigophore; 31,32 , desmonemes. $\times c a .2000$.

Figs. 33-36. Lizzia blondina: 33, 34, microbasic euryteles; 35, 36, desmonemes. $\times$ ca. 2000.

\section{Bougainvillia ramosa (van Beneden).}

One adult male only examined $(2 \cdot 2 \mathrm{~mm}$. diameter).

Two kinds: microbasic euryteles and desmonemes.

Euryteles: $8-9 \times 3.5-4 \mu$ undischarged.

Desmonemes: $4.5-5 \cdot 5 \times 3-3.5 \mu$ undischarged.

These nematocysts were similar in shape and appearance to those of Lizzia blondina (Figs. 33-36).

Bougainvillia britannica Forbes.

Two kinds, microbasic euryteles and desmonemes (Figs. 23-25).

Euryteles: IO-II $\times 3.5-4 \mu$ undischarged, $9 \times 3 \mu$ discharged.

Desmonemes: 6-6.5 $\times 3.5-4 \mu$ undischarged. 
Of these the euryteles only occur in the mouth tentacles; both kinds of nematocysts are found in the marginal tentacles, the desmonemes being the more abundant.

\section{Lizzia blondina Forbes.}

Two kinds: microbasic euryteles and desmonemes (Figs. 33-36).

Present in marginal tentacles and mouth tentacles:

Euryteles: 7-10 $\times 3-5 \mu$ undischarged, $6-7.5 \times 2.5-3.5 \mu$ discharged.

Present in tentacles only:

Desmonemes: $4.5-6 \times 2.5-3.5 \mu$ undischarged.
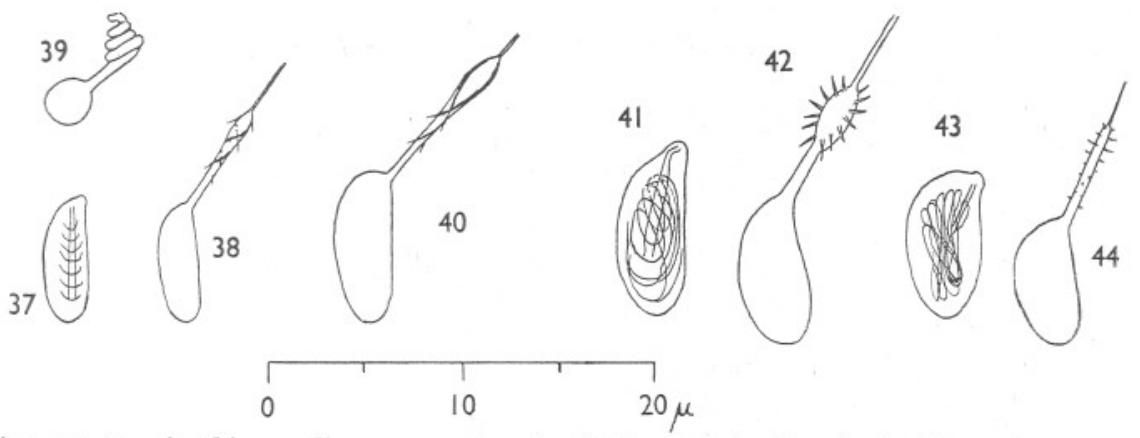

Figs. 37-40. Amphinema dinema: 37, 38, microbasic euryteles from hydroid; 39, desmoneme from hydroid; 40, microbasic eurytele from medusa. $\times$ ca. 2000 .

Figs. 4I-44. Leuckartiara octona: 4I, 42, microbasic euryteles; 43, 44, microbasic mastigophores. $\times c a .2000$.

Rathkea octopunctata (M. Sars).

Two kinds: microbasic euryteles and desmonemes (Figs. 26-32).

Present in marginal tentacles and oral tentacles:

Euryteles:

In oral tentacles: IO-I $2 \times 3-4 \mu$ undischarged, $8-9 \times 2 \cdot 5-3 \cdot 2 \mu$ discharged.

In marginal tentacles: 6-10.5 $\times 2.5-4 \mu$ undischarged (mostly 6-8 $\mu$ ), $5-7 \cdot 5 \times \mathrm{I} \cdot 5-3 \mu$ discharged.

Present in marginal tentacles only:

Desmonemes: $3-5 \times 2-3 \mu$ undischarged.

Sometimes the microbasic euryteles appear as microbasic mastigophores (Fig. 29). This was especially so in one specimen in which the majority appeared to be microbasic mastigophores.

Amphinema dinema (Pér. \& Les.).

In the hydroid and newly liberated medusa there are two kinds, microbasic euryteles and desmonemes. In the adult medusa there is only one kind, microbasic euryteles (Figs. 37-40). 
HYDROID.

Euryteles: 6.5-7.5 $\times 2-2.5 \mu$ undischarged.

Desmonemes: $3.5-4.5 \times 2-2.5 \mu$ undischarged, $2.5 \times 2 \mu$ discharged.

Medusa.

Newly liberated:

Euryteles: $6-7 \times 2 \mu$ undischarged.

Desmonemes: $3.5-4 \times 2 \mu$ undischarged.

Adult:

Present in marginal tentacles and mouth lips.

Euryteles: $7-9.5 \times 2-3.5 \mu$ undischarged, $6.5-7.5 \times 2-2.5 \mu$ discharged.

\section{Amphinema rugosum (Mayer).}

One specimen $c a .2 \mathrm{~mm}$. high only seen. There was only one kind, microbasic eurytele (not figured).

Euryteles: $8-9 \times 2 \mu$ undischarged.

\section{Leuckartiara octona (Fleming).}

There appear to be quite definitely two kinds, microbasic euryteles and microbasic mastigophores (Figs. 4I-44).

Present in tentacles and mouth lips:

Euryteles: 8-10.5 $\times 3-4.5 \mu$ undischarged.

Present (?) only at base of tentacles or on umbrella margin:

Mastigophores: $7 \times 3.5-4 \mu$ undischarged.

At first I thought that there were only euryteles present, but subsequent examinations showed that there were undoubtedly also mastigophores, but these were much fewer. They appeared as small groups, and I was unable to make certain whether they were limited to the base of the tentacle or the umbrella margin. They were certainly not present in the main body of the tentacle. The mastigophores are shorter and more plump than the euryteles.

Weill (1934, p. 392) states that in L. octona from Wimereux there were only microbasic mastigophores, IO-I $2 \mu$ long, present in the tentacles and mouth lips.

\section{Willia stellata Forbes.}

I have unfortunately been unable to obtain any living specimens of this interesting medusa. I have, however, had its hydroid, Lar sabellarum, and its nematocysts are sufficiently interesting to be described here. There were three kinds, macrobasic mastigophores, microbasic euryteles and desmonemes (Figs. $45 a-j$ ).

Mastigophores: $24-33 \times 9-13 \mu$ undischarged.

In some specimens treated with acetic acid or distilled water the distal end of the hamp swelled into an ampulla, like that in the macrobasic eurytele of Zanclea (Fig. $45 d$ ). 


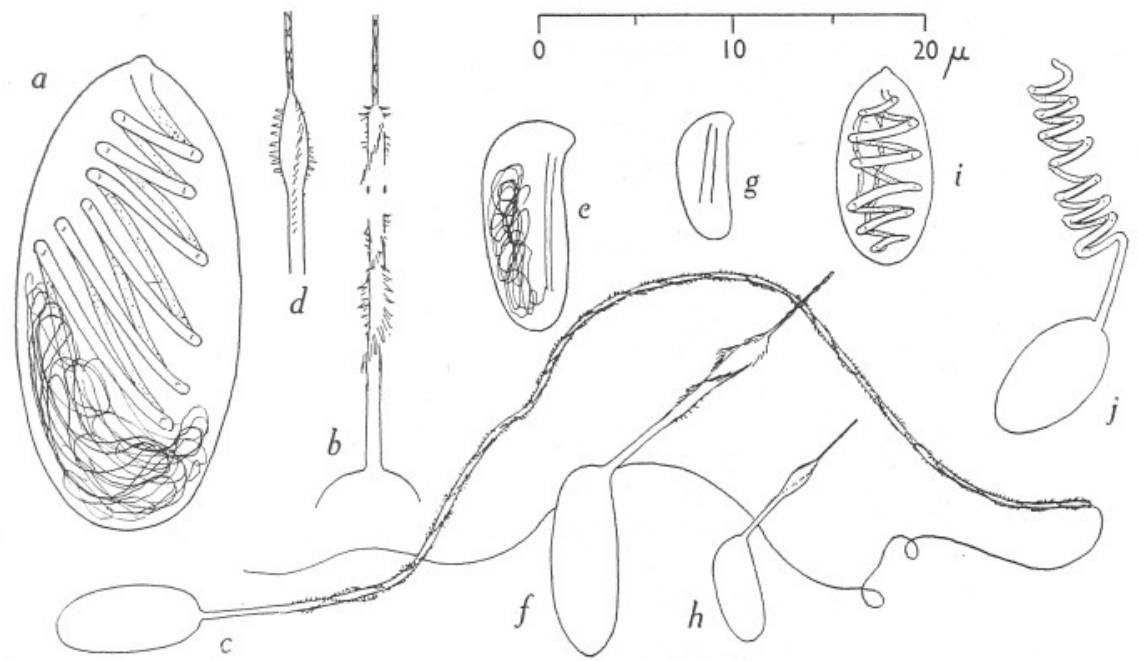

Fig. 45. Lar sabellarum hydroid: $a-d$, macrobasic mastigophores $(c, \times c a .600) ; e-h$, microbasic euryteles; $i-j$, desmonemes. $\times c a .2000$.

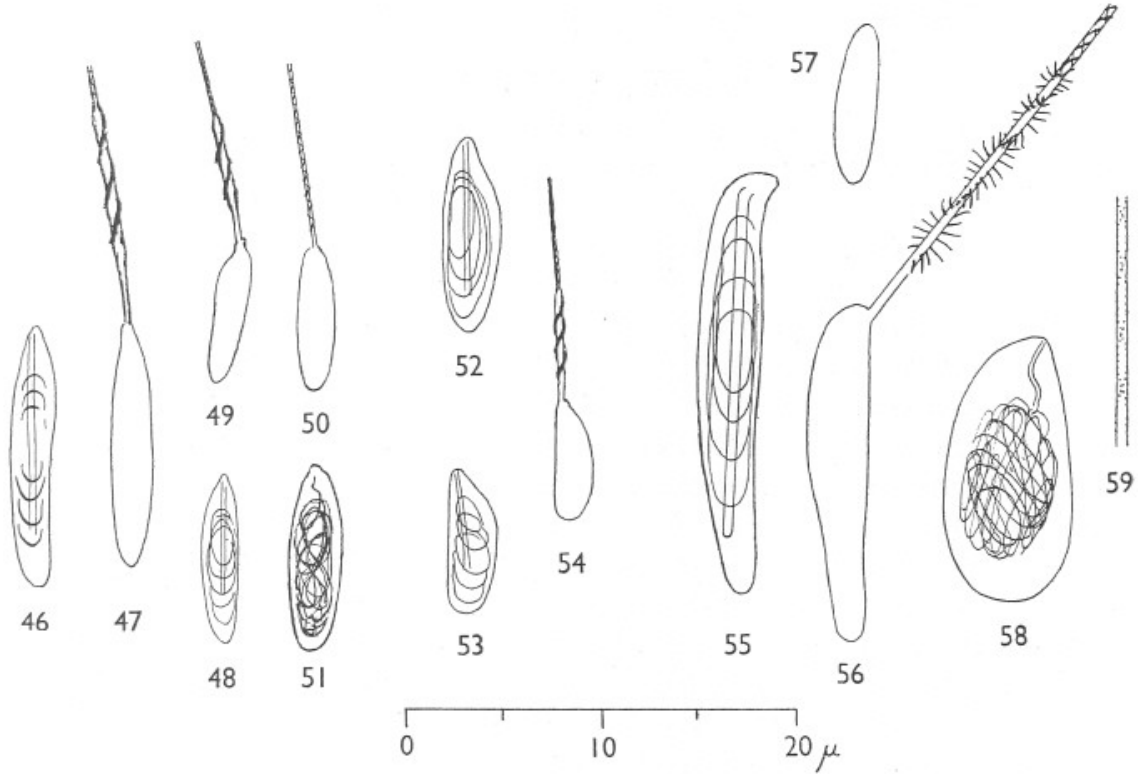

Figs. 46-5I. Phialidium hemisphericum: 46, 47, large microbasic mastigophores from exumbrella; 48, 49, microbasic mastigophores from tentacle; 50, 5I, atrichous haplonemes. $\times$ ca. 2000 .

Figs. 52-54. Phialella cymbaloides: microbasic mastigophores. $\times$ ca. 2000.

Figs. 55-59. Saphenia gracilis: 55, 56, basitrichous haplonemes; 57, very small ? basitrichous haploneme from margin of umbrella; 58, atrichous haploneme, with portion of thread, 59. $\times$ ca. 2000. 
Euryteles:

Large: 9-13 $\times 4-5 \mu$ undischarged, 9.5-10 $\times 3-3.5 \mu$ discharged.

Small: $6 \cdot 5-7 \times 2 \cdot 5-3 \mu$ undischarged, $5.5 \times 2 \mu$ discharged.

Desmonemes: $10 \times 5 \mu$ undischarged.

The desmonemes had unusually long threads for Anthomedusae, with as many as seven coils.

The macrobasic mastigophores were present only in the nematocyst pad on the proboscis.

\section{LEPTOMEDUSAE}

Mitrocomella brownei (Kramp).

One adult female only seen. There were two kinds, basitrichous haplonemes and atrichous haplonemes (Figs. 60-65).

Present in marginal tentacles and mouth lips:

Basitriches: two sizes.

Large: $\mathrm{I} 4-\mathrm{I} 6 \times 4-5 \mu$ undischarged, $\mathrm{I} 3-\mathrm{I} 4 \times 3-3.5 \mu$ discharged.

Small: $8.5-$ II $\times 2-2 \cdot 5 \mu$ undischarged, $8-9 \times 2 \mu$ discharged.

Atriches: II-I2 $\times 4 \mu$ undischarged, IO-II $\times 3.5 \mu$ discharged.

The armature on the base of the basitriches is very strong, the barbs being very long and pronounced.

\section{Phialidium hemisphericum (L.).}

There were two kinds, atrichous haplonemes and what appeared to be microbasic mastigophores. These were quite clearly mastigophores when first discharged, but, later, possibly due to pressure, the thread swells up so that they appear as basitrichous haplonemes (Figs. 46-5I).

? Mastigophores: these were of two sizes:

Large: $\mathrm{I} 2-\mathrm{I} 4 \times 2-3 \mu$ undischarged, II $-\mathrm{I} 3 \times \mathrm{I} \cdot 5-2 \mu$ discharged.

Small: $8-\mathrm{I} 0 \times 2 \mu$ undischarged, $7 \times \mathrm{I} \cdot 5 \mu$ discharged.

The large mastigophores occurred on the umbrella. Some of the small mastigophores were mussel-shaped, but most were almond-shaped. The small ones were by far the most numerous.

Atriches: 9-10 $\times 2.5-3 \mu$ undischarged.

It was only after I had examined a number of specimens that I found a discharged atriche. They can easily be confused with the others in their undischarged state, being of approximately the same size. In one of the later specimens I examined, when placed in distilled water and magenta, only the atriches discharged. They were then seen to be quite common, and were subsequently found in many specimens.

Weill (1934, p. 464) states that in this medusa from Wimereux there was only one type of nematocyst, a basitrichous haploneme, IO-I2 $\mu$ long. $\mathrm{He}$ found, however, that in the hydroid of this species, Clytia johnstoni, there were both basitriches and microbasic mastigophores. It seems possible that he may have been misled by the swelling of the thread. 
I examined medusae newly liberated from the hydroid and found both mastigophores and atriches present. In the hydroid I found mastigophores of two sizes but saw no atriches. I do not regard this as proof that they were not present.

When examining the mastigophores in this species and in Phialella cymbaloides I could never see for certain whether the spirals on the hamp were composed of spines. I imagined that this was so, for at the end of each dark diagonal line there was a slight projection. This may, however, have been an optical illusion due to the continuation of the spiral round the hamp. There are three spirals present, but I have not indicated these in Figs. 47 and 49 because it would not have been possible to draw them satisfactorily to so small a scale. I have therefore shown the appearance of the hamp when the upper surface is brought into focus. Thus in the small nematocysts there appear to be two dark diagonal lines and in the large nematocysts three diagonals.

\section{Phialella cymbaloides (van Beneden).}

One kind: ? microbasic mastigophores or basitrichous haplonemes (Figs. 52-54). I experienced the same swelling of the thread in these as in Phialidium. There were two sizes.

Small, in marginal tentacles: $6-9 \times 2-3 \mu$ undischarged.

Large, in mouth lips: $9-13 \times 2.5-4 \mu$ undischarged.

It is curious that I saw no atriches, for these seem to be present in most Leptomedusae.

\section{Eucheilota clausa (Hincks).}

There appear to be two kinds, atrichous haplonemes and possibly basitrichous haplonemes (Figs. 66-74). As with Phialidium hemisphericum, however, the basitriches in at least one specimen appeared as microbasic mastigophores immediately after discharge.

? Basitriches: these nematocysts occurred in two distinctly different shapes, (i) in the shape of an almond; (ii) in the shape of a mussel, Mytilus.

The almond-shaped basitriches were of two sizes and occurred in the tentacles and mouth lips: I2-I9 $\times 3-4 \mu$ undischarged, and 6.5-I0.5 $\times \mathrm{I} \cdot 5-3 \mu$ undischarged. The smaller of these were more numerous in the mouth lips than the larger.

The mussel-shaped basitriches appeared to be confined to the umbrella margin and had longer barbs on their basal armature.

Atriches: $c a$. $\mathrm{I} 2-\mathrm{I} 3 \times 4-5 \mu$ undischarged.

\section{Saphenia gracilis (Forbes \& Goodsir).}

There were three kinds, basitrichous haplonemes and atrichous haplonemes, and very small ? haplonemes or mastigophores (Figs. 55-59).

Basitriches: these were of two sizes. 

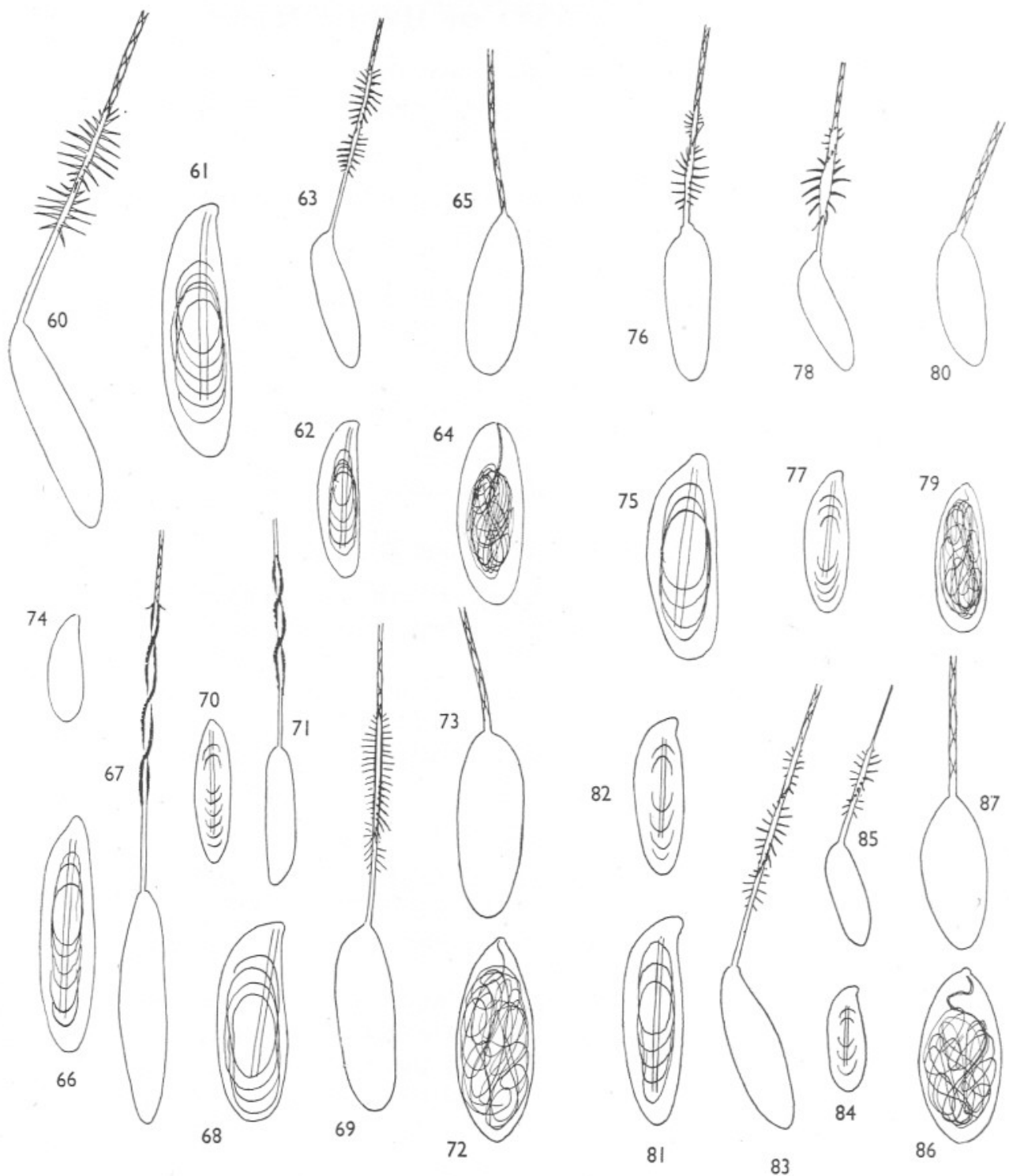

$$
72
$$
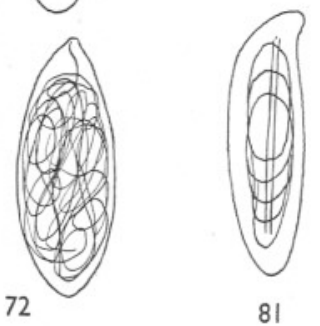

83

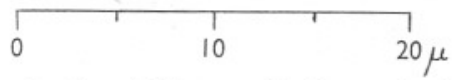

Figs. 60-65. Mitrocomella brownei: 60-63, basitrichous haplonemes; 64, 65, atrichous haplonemes. $\times c a .2000$.

Figs. 66-74. Eucheilota clausa: 66-71, ? basitrichous haplonemes; 68,69 , mussel-shaped form; 72,73 , atrichous haploneme; 74, very small ? basitrichous haploneme. $\times c a .2000$.

Figs. 75-80. Helgicirrha schulzei: 75-78, basitrichous haplonemes; 79, 80, atrichous haplonemes. $\times c a .2000$.

Figs. 8I-87. Octorchis gegenbauri: 8I-85, ? microbasic mastigophores; 86, 87, atrichous haplonemes. $\times c a .2000$. 
Large, in marginal tentacles: $18-28 \times 3-4 \mu$ undischarged.

Small, in mouth lips: IO-I $3 \times 2 \cdot 5-3 \mu$ undischarged.

Atriches: $12-16 \times 4-7 \mu$ undischarged.

The very small nematocysts, $7-8 \times 2-2.5 \mu$ undischarged, were present on the umbrella margin. Unfortunately I was unable to see any discharged, so could not make certain of their type.

Weill (1934, p. 460) states that in $S$. gracilis from Wimereux there were two kinds, atriches $15 \times 7 \mu$ and basitriches $22 \times 5 \mu$.

\section{Octorchis gegenbauri Haeckel.}

Two kinds, atrichous haplonemes and basitrichous haplonemes, the smaller of which may have been basitrichous mastigophores (Figs. 8I-87).

Basitriches: these were of two sizes in the tentacles and margin:

Large: $\mathrm{I} 2-\mathrm{I} 5 \times 3.5-5 \mu$ undischarged.

Small: $7-8.5 \times 2-2.5 \mu$ undischarged.

In the mouth lips I saw only one size, $8 \cdot 5-10 \times 2 \cdot 5-3 \mu$ undischarged.

Atriches: 9-13 $\times 4-5.5 \mu$ undischarged.

I could not make out for certain whether the smaller basitriche nematocysts were haplonemes or mastigophores.

Helgicirrha schulzei Hartlaub.

Two kinds: basitrichous haplonemes and atrichous haplonemes (Figs. 75-80).

Basitriches: 9-13.5 $\times 3-4 \mu$ undischarged.

Atriches: 9-I2 $\times 3-4 \mu$ undischarged.

All types were present in the tentacles but I could see only small basitriches in the mouth lips.

\section{SIPHONOPHORA}

\section{Muggiaea atlantica Cunningham.}

On the tentilla there are three kinds, desmonemes on the terminal filament, and large microbasic mastigophores and atrichous haplonemes in the battery (Figs. 88a-f).

Desmonemes: 7 -IO $\times 4-6 \mu$ undischarged.

Mastigophores: $36-43 \times 6-7.5 \mu$ undischarged, $33-36 \times 6 \mu$ discharged.

Atriches: 13-18 $\times 3-4 \mu$ undischarged (often anisorhize in form).

Interspersed among the desmonemes on the terminal filament there are

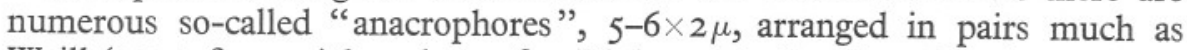
Weill (1934, fig. III) has shown for Diphyes spiralis. Since the desmonemes show a range in size down to that of the "anacrophores" I am inclined to think that the "anacrophores" may be immature desmonemes at the stage before they become rounded; otherwise it is difficult to understand whence so many desmonemes originate. Similarly I observed that the immature atrichous 


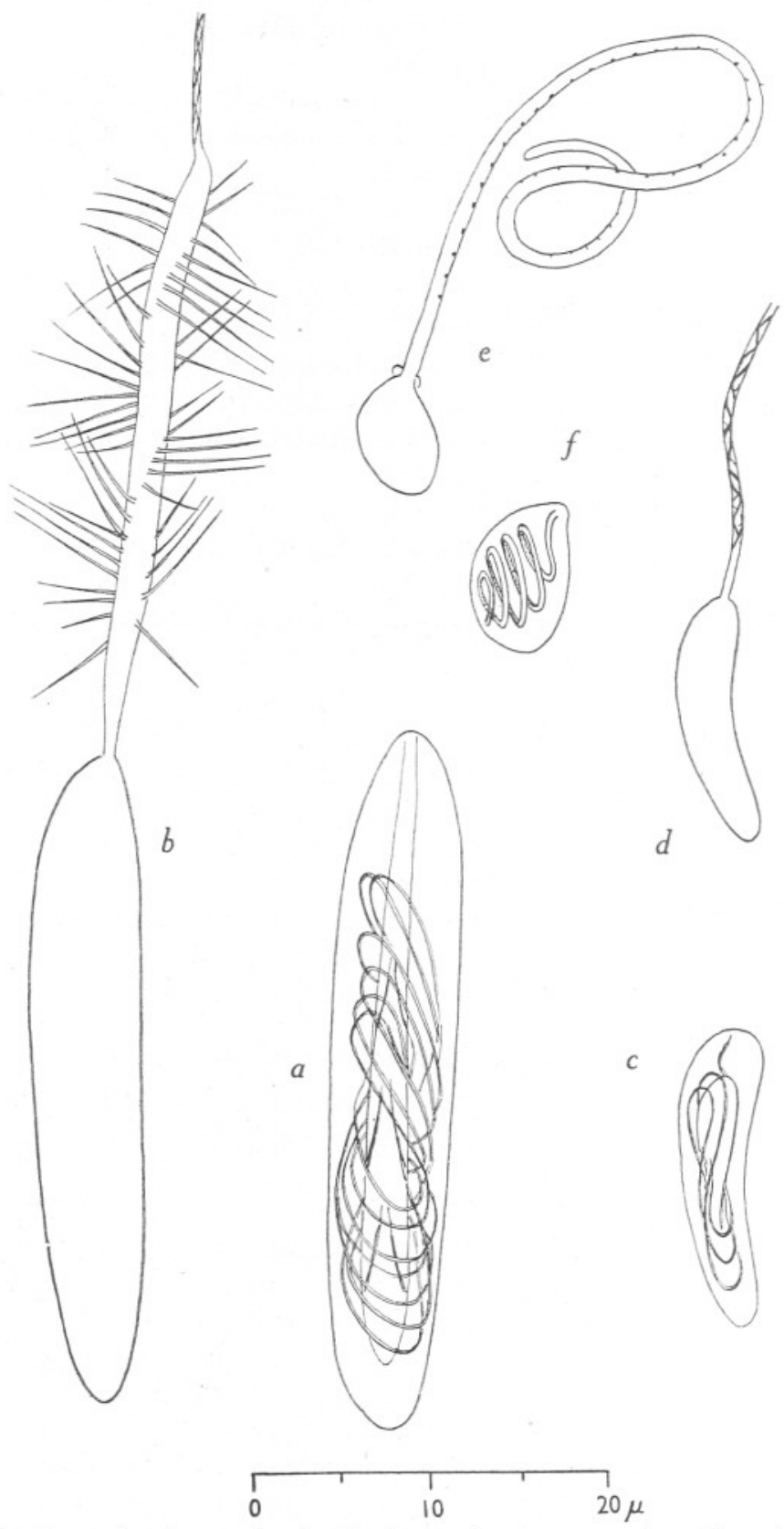

Fig. 88. Muggiaea atlantica: $a, b$, microbasic mastigophores; $c, d$, atrichous haplonemes; $e, f$, desmonemes ( $e$, thread uncoiled). $\times c a .2000$. 
haplonemes, 9-I $2 \times 2 \mu$, would partly discharge and appear like "anacrophores", having a dilated basal portion with a terminal filament from the end of which the remaining un-everted portion of the thread could be traced back to the capsule in which it was coiled. On these grounds I suggest that the so-called "acrophores" and "anacrophores" recorded in Siphonophores may be merely stages in the development of other nematocysts.

\section{Discussion}

The nematocysts may be regarded as characters of a medusa worthy of description, just as much as any of the other structures which are dealt with when a detailed description is made of any one species. But, apart from this aspect, it has been repeatedly urged that a knowledge of their structure may give a clue to the phylogenetic relationships of species of coelenterates whose relationships are not made clear by other known characters (e.g. Stephenson, I929; Weill, 1934). With this further addition to our knowledge of the nematocysts of medusae, it is therefore not without interest to summarize the results for medusae alone, as Weill has done for so many groups. I have therefore given a table (p. I63) showing the distribution of the different types of nematocysts among a number of species of Anthomedusae and Leptomedusae. In this table a cross in brackets indicates that I was uncertain to which category a nematocyst should belong; the two alternative categories are therefore shown in this manner whenever I was in doubt. The medusae have been arranged in their order of classification into the different families that are more generally accepted at the present time.

A first glance at this table shows that most of these medusae fall into four main groups as regards their nematocyst characters. Of these the first, the Tubulariidae, are set apart by having four types of nematocysts.

The other three groups comprise the Corynidae and Eleutheriidae in which there are two kinds, desmonemes and stenoteles; the Clavidae and Bougainvilliidae or Margelidae with two kinds, desmonemes and microbasic euryteles; and thirdly the Leptomedusae as a whole which have two kinds, atrichous haplonemes and the basitrichous haploneme-microbasic mastigophore type (except Phialella cymbaloides). There is yet a fifth group, the Pandeidae, whose adults lack all types of nematocysts except the microbasic eurytele, with the addition of a microbasic mastigophore in Leuckartiara.

It can thus be seen that the distribution of nematocyst types fits very well with the accepted classification of the medusae based on other characters. Some reliance may therefore be placed on them as classificatory characters. Their value has been shown quite definitely for Zanclea and the Eleutheriidae by Weill (1934, 1936b). Zanclea has indeed been set apart from the Corynidae on account of its very remarkable tentacle structure and because its gonads do not surround the manubrium. Yet its hydroid is very corynid in appearance. Its nematocysts show its relationship with the tubularian and corynid groups 
in the stenoteles. It is separated from them, however, by the absence of desmonemes, which occur in both the other groups, and by the presence of the remarkable macrobasic euryteles. The position of the Eleutheriidae has long been a source of discussion, but their nematocysts show quite clearly a close relation with the Corynidae.

When we consider the other groupings we see that the hydroid of Willia stellata stands apart in having macrobasic mastigophores which are not found in any of the other medusae. This is further evidence justifying the formation of a separate family, the Williidae, to hold this medusa and its near relatives. It is also of great interest to find that in its nematocysts this species shows a relationship with the clavid-bougainvilliid group in the presence of desmonemes and absence of stenoteles. It is thus in its relationship to this group somewhat like Zanclea in its relationship to the tubulariid-corynid group. Both species possess a unique type of nematocyst and both have somewhat remarkable armature on the exumbrella. Willia shows no relationship to the Leptomedusae in its nematocysts and is thus probably correctly placed in the Anthomedusae.

There are other points of interest shown in the table, such as the apparent relationship between Rathkea and Lizzia and Bougainvillia, but until more species are studied it seems a little premature to discuss such relationships in detail.

It is a noticeable feature that while the Anthomedusae are thus divided into a number of distinct groups by their nematocyst characteristics, the Leptomedusae as a whole show no such division (cf. Weill, I934, p. 478). This is in agreement with the great diversity of form shown by the Anthomedusae as compared with the Leptomedusae. It is unfortunate, because I had hoped that by examining a number of widely separated genera of Leptomedusae some of their relationships might have been shown by their nematocysts.

This preliminary review of medusan nematocysts has shown that the opinion that their study may be of value in showing phylogenetic relationships is justified and that more observations should be made. When we consider their value as specific characters, however, it is evident that a great deal more research will have to be done on the dimensions and variations of the nematocysts in individual species. It is true that a study of the accompanying illustrations of the nematocysts of Leptomedusae shows that a few of them are quite distinctive, but on the whole they are extraordinarily alike. All the species so far studied are quite easily distinguishable by other morphological characters, and the value of nematocysts as specific characters will have to be shown in species that are closely alike and in which as yet specific distinctions remain in considerable doubt. Typical examples of such medusae are the species of Obelia and of Aequorea. I have not myself examined such species yet. If the differences are small, as they are quite likely to be, it is necessary for the observer to have had considerable experience in observing 
ANTHOMEDUSAE

Tubulariidae

Steenstrupia nutans Ectopleura dumortieri ${ }^{\star}$

Corynidae

Sarsia eximia

Sarsia prolifera ${ }^{\star}$

Purena gemmifera

Eleutheriidae

Eleutheria dichotoma Cladonema radiatum

Pteronemidae

Zanclea costata?

Clavidae

Oceania armata ${ }^{\star}$

Bougainvilliidae-Margelidae Bougainvillia ramosa Bougainvillia britannica

Lizzia blondina

Rathkea octopunctata

Pandeidae

Amphinema dinema

Amphinema rugosum

Leuckartiara octona

Williidae

Willia stellata (Hydroid)

LEPTOMEDUSAE

Mitrocomidae

Mitrocomella brownei

Eucopidae

Phialidium hemisphericum

Phialella cymbaloides

Eucheilota clausa

Saphenia gracili

Octorchis gegenbauri

Eirene viridula

Helgicirrha schulzei

Aequoridae

Aequorea forskalia

* Weill (1934)

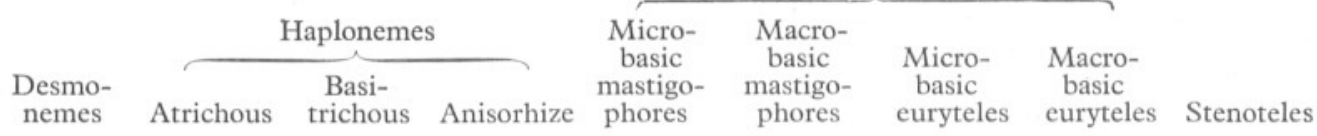

\begin{tabular}{|c|c|c|c|}
\hline$(x)$ & . & $(x)$ & . \\
\hline$\times$ & . & . & . \\
\hline$\cdots$ & . & . & $\cdots$ \\
\hline$\ddot{y}$ & $\begin{array}{l}\cdots \\
\cdots\end{array}$ & $\cdots$ & $\therefore$ \\
\hline$\therefore$ & & & \\
\hline . & 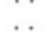 & .. & $\because$. \\
\hline . & $\ldots$ & $\ldots$ & $\times$ \\
\hline$\cdots$ & . & $x$ & . \\
\hline. & $\ldots$ & $x$ & $\ldots$ \\
\hline . & $\ldots$ & $x$ & . \\
\hline & $\cdots$ & $\begin{array}{l}x \\
x\end{array}$ & $\cdots$ \\
\hline 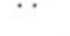 & $\cdots$ & & $\cdots$ \\
\hline$\cdots$ & $\ldots$ & $x$ & . \\
\hline & . & $\times$ & $\cdots$ \\
\hline & $\cdots$ & $x$ & $\cdots$ \\
\hline & $\times$ & $\times$ & $\cdots$ \\
\hline
\end{tabular}

$\begin{array}{ccc}\times & . & \cdots \\ (\times) & \ldots & (\times) \\ (\times) & \cdots & (\times) \\ (\times) & \cdots & (\times) \\ \times & \cdots & \cdots \\ \times & \cdots & \ddot{x} \\ \ddot{\times} & \cdots & \cdots \\ \times & \ldots & (\times)\end{array}$

$\cdots$
$\cdots$
$\cdots$
$\cdots$
$\cdots$
$\cdots$
$\ldots$

¥ Present only in medusa just liberated from hydroid. 
nematocysts. Only then will he know what kind of differences to look for. Examination of closely related species must, also, be made by the same observer. There is liable to be a pronounced personal factor in observing these minute structures under high powers of the microscope. On this account interpretations of structure may be quite different by different observers, because the same kinds of nematocysts may appear so different unless examined in exactly the same positions. In this respect it seems rather significant that when I compare my results with those of so eminent a specialist as Dr Robert Weill I find that I differ from his conclusions in no less than five out of the six species that we have both studied.

\section{SUMMARY}

The nematocysts of twenty species of Hydromedusae occurring at Plymouth are described. Of these, twelve were Anthomedusae and seven were Leptomedusae, and one was the Siphonophore, Muggiaea atlantica. The medusae fit very well into the generally accepted classification as regards the types of nematocysts they possess.

Lar sabellarum, the hydroid of Willia stellata, has a type of nematocyst not found in the other species-a macrobasic mastigophore. This is a further justification for the formation of a separate family, the Williidae, to hold this species and its relations.

While the Anthomedusae are clearly split up into distinct groups as regards their types of nematocysts, the Leptomedusae form a single group.

It is suggested that the so-called acrophores and anacrophores recorded in siphonophores may be merely stages in the development of other nematocysts.

It is urged that much more research is required on variation in size and structure of nematocysts in individual species before they can be used as specific characters for separating doubtful species.

\section{REFERENCES}

Allman, George James, I87i-2. A monograph of the gymnoblastic or tubularian hydroids. Ray Society, pp. I-450.

Papenfuss, Emma Johnstone, I936. The utility of the nematocysts in the classification of certain Scyphomedusae. I. Lunds Universitets Ársskrift, N.F., Avd. 2, Bd. 3I, Nr. II, 26 pp. (Kungl. Fysiograf. Sållsk. Handl., N.F., Bd. 46, Nr. II.)

Ranson, G., I937. Cnidactine et cnidothylacies chez les Anthoméduses. Bull. Soc. Zool. France, Tome LxII, pp. 318-29.

Russell, F. S. \& ReES, W. J., 1936. On rearing the hydroid Zanclea implexa (Alder) and its medusa Zanclea gemmosa McCrady, with a review of the genus Zanclea. Fourn. Mar. Biol. Assoc., Vol. xxI, pp. I07-29.

Stephenson, T. A., 1929. On the nematocysts of sea anemones. Fourn. Mar. Biol. Assoc., Vol. xvI, pp. I73-200. 
WeILl, RoBERT, I934. Contribution à l'étude des cnidaires et de leurs nématocystes. I. Recherches sur les nématocystes (Morphologie-Physiologie-Développement). II. Valeur taxonomique du cnidome. Trav. Stat. Zool. Wimereux, Tome x, pp. I-347 and Tome XI, pp. 349-70I.

I 936 a. Au sujet de la définition et de la validité du genre Güntherella Weill 1934 (Hydrozoaires). Bull. Soc. Zool. France, Tome LxI, pp. 526-32.

I936 b. Le cnidome des Cladonémides Eleutheria dichotoma et Cladonema radiatum, son cycle et son interprétation. C.R. Acad. Sci., Paris, Tome 203, pp. 8I6-I8. 